\title{
Velocity and concentration profiles of saline and turbidity currents flowing in a straight channel under quasi-uniform conditions
}

\author{
M. Stagnaro and M. Bolla Pittaluga \\ Department of Civil, Chemical and Environmental Engineering, University of Genova, Italy \\ Correspondence to: M. Stagnaro (mattia.stagnaro@unige.it) \\ Received: 15 October 2013 - Published in Earth Surf. Dynam. Discuss.: 18 November 2013 \\ Revised: 18 February 2014 - Accepted: 22 February 2014 - Published: 25 March 2014
}

\begin{abstract}
We present a series of detailed experimental observations of saline and turbidity currents flowing in a straight channel. Experiments are performed by continuously feeding the channel with a dense mixture until a quasi-steady configuration is obtained. The flume, $12 \mathrm{~m}$ long, is characterized by a concrete fixed bed with a uniform slope of 0.005 . Longitudinal velocity profiles are measured in ten cross sections, $1 \mathrm{~m}$ apart, employing an ultrasound Doppler velocity profiler. We also measure the density of the mixture using a rake of siphons sampling at different heights from the bottom in order to obtain the vertical density distributions in a cross section where the flow already attained a quasi-uniform configuration. We performed 27 experiments changing the flow discharge, the fractional excess density, the character of the current (saline or turbidity) and the roughness of the bed in order to observe the consequences of these variations on the vertical velocity profiles and on the overall characteristics of the flow. Dimensionless velocity profiles under quasi-uniform flow conditions were obtained by scaling longitudinal velocity with its depth averaged value and the vertical coordinate with the flow thickness. They turned out to be influenced by the Reynolds number of the flow, by the relative bed roughness, and by the presence of sediment in suspension. Unexpectedly, the densimetric Froude number of the current turned out to have no influence on the dimensionless velocity profiles.
\end{abstract}

\section{Introduction}

Turbidity currents flowing in submarine canyons are recognized as preferential conduits for sediment transfer from shallow to deep water. They have a tremendous impact on the deep-sea environment since they affect the ecosystem in various ways, including burial by sediment deposition, exposure by sediment removal, and food supply. Moreover, they are of great engineering relevance due to their ability to reach extremely high velocities that represent a serious geohazard for deep water installations. Additionally, since the majority of sandstones in the geologic record were deposited from rivers or from turbidity currents, they are also extremely significant in the research and exploitation of hydrocarbon reservoirs.

In spite of their relevance, direct observation of the active process has proven extremely difficult since these events are short lived, located at specific sites, unpredictable and, in some circumstances, highly disruptive. A notable exception is the recent field observation performed by $\mathrm{Xu}$ et al. (2004), who successfully measured vertical profiles of downstream velocity for four flow events over the space of 1 year, at three locations down Monterey Canyon, California. Due to these difficulties, the majority of the investigations aimed at understanding the dynamic of turbidity currents has been either through theoretical investigations or through experimental observations.

From a theoretical point of view it is certainly worth mentioning the milestone paper of Parker et al. (1986) where a theory for slowly varying flows was first derived describing the dynamics of a turbulent flow through a set of four layeraveraged equations: continuity and momentum equations for the fluid phase, continuity equation of the suspended sediment and equation describing the balance of turbulent kinetic energy. Such theoretical framework demonstrated that 
turbidity currents could initiate larger and faster flows capable of transporting coarser material by the resuspension of particles from the bed. Such theoretical results were recently substantiated by the experimental observations of Sequeiros et al. (2009). In terms of laboratory investigations, Parker et al. (1987) performed a series of experimental observations on turbidity currents flowing over an erodible bed. Such pioneering experiments were employed to establish approximate similarity laws for the velocity and concentration distributions. Normalized velocity and concentration profiles showed a similarity collapse indicating little systematic variation in grain size or bed slope. However, only supercritical currents were studied and the vertical structure was strongly affected by the presence of bedforms invariably found at the end of experiments. In a subsequent experiment, Garcia and Parker (1993) studied the spatial evolution of saline underflows allowed to flow down a nonerodible $5 \mathrm{~m}$ long sloping bed with the slope fixed to 0.08 , followed by an horizontal reach. In the first reach a trench filled with sediment was created to allow accurate experimental determination of the ability of the current to entrain sediments. The same experimental setting was then employed by Garcia (1994) to study the depositional structure of turbidity currents laden with poorly sorted sediments. The similarity collapse of measured flow velocity was quite good for the supercritical region of the flows, but, on the other hand, the data collapse for the subcritical region of the flows showed a fair amount of scatter. Altinakar et al. (1996a) performed a large number of experiments on turbidity currents employing either salt or sediments to generate the current. However, they primarily focused their attention on the head rather than on the body of the current. The same authors (Altinakar et al., 1996b) later showed that velocity and concentration distributions could be well represented by similarity profiles independently on the values attained by the main dimensionless parameters (namely densimetric Froude number, Rouse number, relative bed roughness, etc.), once both profiles are scaled with the values attained by the corresponding quantities at the velocity peak. Recently, Sequeiros et al. (2010) somehow contradicted the previous findings showing that the vertical profiles of streamwise flow velocity and fractional excess density, due to salt, salt/suspended sediment or suspended sediment alone, of the flow can be consistently represented depending on the Froude number, the grain size of the bed material and the presence or absence of bed forms. Here we wish to integrate these experimental observations with a new set of observations specifically aimed at make some progress on the dimensionless parameters affecting the dynamics of turbidity and saline currents. Our main interest is on the vertical structure of both velocity and concentration profiles. Besides reconsidering the well known influence of the densimetric Froude number and of the relative bed roughness on the vertical profiles, we will also investigate the effect of the Rouse and Reynolds number on the vertical structures as well as the effects of the presence of sediment on the velocity profiles of the currents. This will be done performing a large number of experiments in a straight flume with a fixed sloping bed. The inflow conditions, namely the flow discharge, the fractional density excess, the nature of the current (saline or turbidity), and the bed roughness will be varied over a wide range in order to cover both subcritical and supercritical flows, and both turbulent and nearly laminar flows.

\section{Description of the experimental apparatus and procedure}

\subsection{Experimental apparatus}

The experiments are performed in a $30 \mathrm{~m}$ long flume, composed by two straight reaches $12 \mathrm{~m}$ long joined by a $180^{\circ}$ bend with a constant radius of $2.5 \mathrm{~m}$. Inside the plexiglass flume, $0.6 \mathrm{~m}$ wide and $0.5 \mathrm{~m}$ deep, a constant bottom slope of 0.005 is realized with concrete starting from the inlet cross section of the flume and proceeding $3 \mathrm{~m}$ after the bend exit where the bottom keeps horizontal until the end of the flume (Fig. 1). Here we will focus our attention on the first straight reach, only, where the flow is capable to reach a quasi-uniform flow condition. With quasi-uniform flow we mean a flow characterized by a flow thickness that is slowly varying in the downstream direction. The reason for the prefix quasi stems from the observation that a perfect uniform flow (flow thickness constant in space) is never met due to water entrainment from above.

At the upstream end of the flume a sluice gate is placed to isolate a small portion of the channel where the dense mixture is injected. In this way, the mixture debouching in the inlet chamber is forced to pass through the sluice gate, allowing us to control the upstream flow thickness of the current by changing its height $h_{0}$. At the downstream end of the flume a dumping tank with a bottom drain is placed in order to avoid upstream effects induced by the filling of the tank with the dense mixture during the experiment.

The mixture of water and sediment (and/or salt) is created in two mixing tanks, each one approximately equal to $2 \mathrm{~m}^{3}$, adding to the fresh water the prescribed amount of salt and sediment, in order to obtain a fluid with the desired density. The fluid inside the tank was stirred by a mixer that allows the sediment to be taken in suspension and the salt dissolved. Before starting the experiments, the flume was pre-filled with fresh water, and its density and temperature were measured such to determine the exact value of excess density between the mixture and the ambient fluid. The dense fluid is put in the channel using a hydraulic pump through a pipe conduit. The flow discharge was adjusted before every experiment, using a recirculation conduit (Fig. 1) where a control valve was opened the required amount to obtain the specified value of flow discharge. The flow rate is measured during the experiment by an orifice flowmeter. 


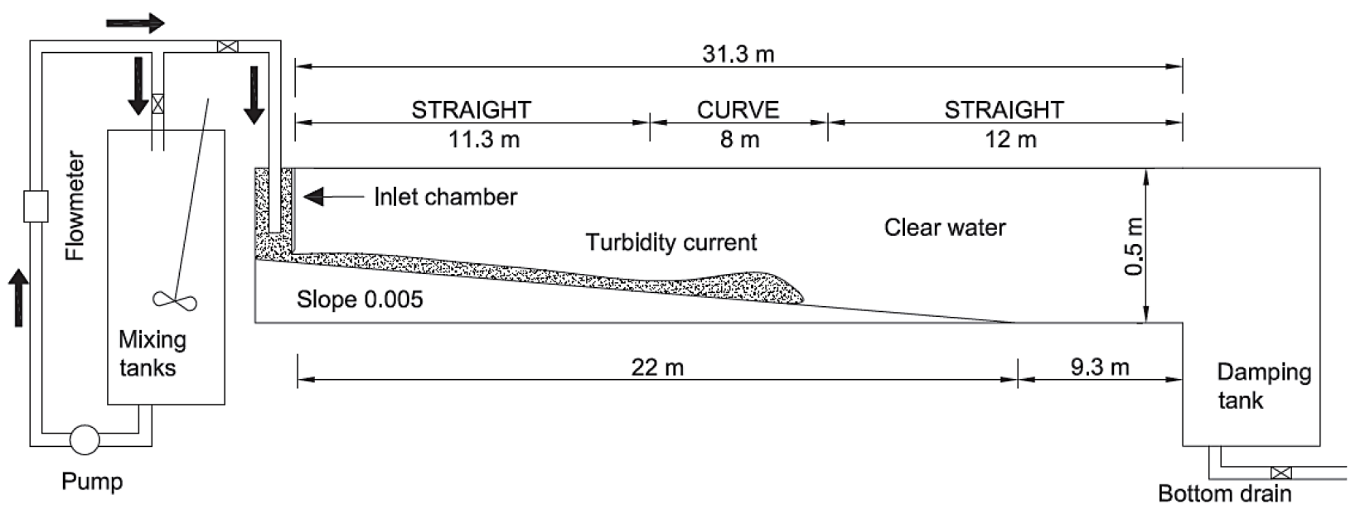

(a)

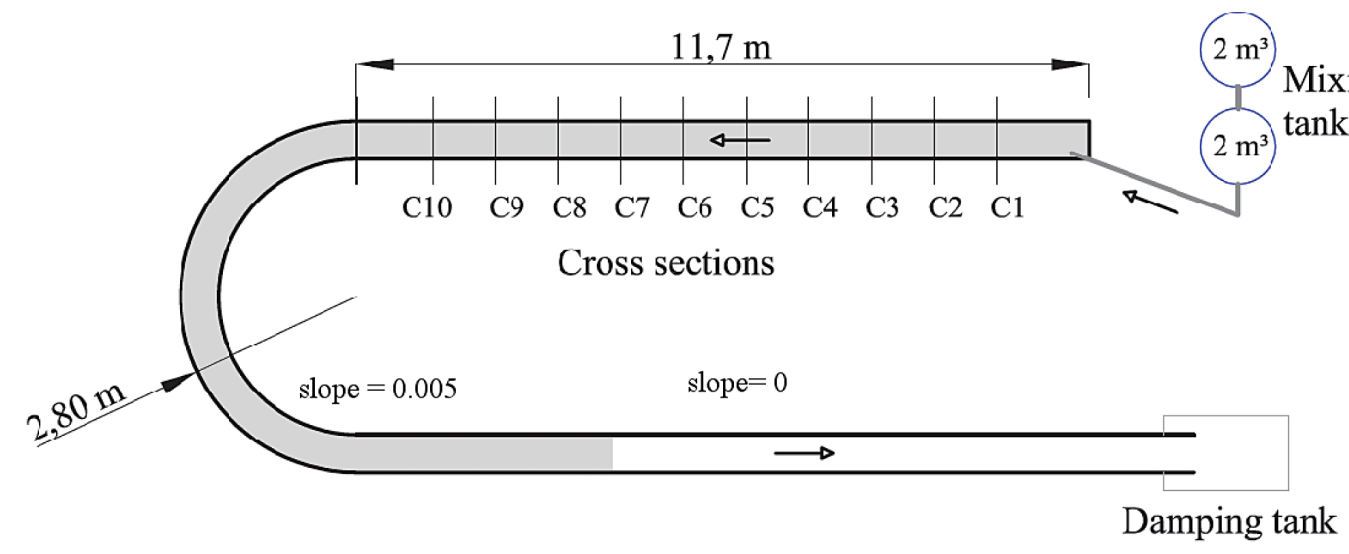

(b)

Figure 1. (a) Sketch and (b) plan view of the turbidity current flume.

A rake of siphons sample a volume of $0.25 \mathrm{~L}$ at ten different elevations along the vertical in order to measure the density distribution in cross section C5 in every run. The density of the fluid is then measured using a density hydrometer. The siphons are operated manually, and start sampling when the current head reaches the end of the flume and the current reaches quasi-steady conditions. This allows us to obtain the density distribution of the flow body, averaged over the time necessary to get the samples. The siphons are placed at 3, 9, $15,25,40,55,70,100,150$, and $200 \mathrm{~mm}$ from the bottom, and sample simultaneously. The suction velocity is set such to be similar to the current velocity, in order to obtain realistic samples at the height each siphon is located.

The ultrasound Doppler velocity profiler (UDVP) DOP2000 is employed to measure longitudinal velocity profiles of the flow. We employ 10 probes simultaneously located in different cross sections (from $\mathrm{C} 1$ to $\mathrm{C} 10$ in Fig. 1) during each experiment. To record the longitudinal profile every probe is placed along the centerline of the flume, partially immersed in the water, pointing upstream and towards the bottom of the flume, with an inclination of $60^{\circ}$ with respect to the horizontal.

\subsection{Experiments performed and experimental procedure}

In this work we focus our attention on 27 experiments whose main characteristics are summarized in Table 1, where we have summarized the main parameters that characterize each experiment. In the first column we report the label of the experiments, whereas in the next three columns we show the values of the excess density, flow rate and the nature of the mixture corresponding to the inlet. In particular, saline underflows are characterized by a mixture of salt ( $90 \%$ in weight) and sediments (10\% in weight), in order to have in the current a sufficient amount of tracer for the UDVP velocimeter. In the fifth and sixth columns we present the values of depth averaged velocity and flow thickness. Such values correspond to cross section $\mathrm{C} 5$, which is the reference section of the straight reach where the results are presented. The corresponding values of the densimetric Froude number and the Reynolds number calculated in the same reference cross section are reported on columns eight and nine, respectively. Finally, the last column indicates if the bed was made of concrete (smooth) or, vice versa, if sediments were glued to the bed (rough). 
Table 1. Summary of the principal characteristics of the 27 experiments performed.

\begin{tabular}{|c|c|c|c|c|c|c|c|c|}
\hline $\begin{array}{l}\text { Exp. } \\
\text { no. }\end{array}$ & $\begin{array}{c}\text { Excess } \\
\text { density } \\
\Delta \rho / \rho\end{array}$ & $\begin{array}{c}\text { Flow } \\
\text { discharge } \\
q_{0}\left(\mathrm{~m}^{2} \mathrm{~s}^{-1}\right)\end{array}$ & $\begin{array}{c}\text { Mixture } \\
\text { salt-sand } \\
(\%)\end{array}$ & $\begin{array}{l}\text { Average } \\
\text { velocity } \\
U\left(\mathrm{~m} \mathrm{~s}^{-1}\right)\end{array}$ & $\begin{array}{c}\text { Average } \\
\text { flow depth } \\
h(\mathrm{~m})\end{array}$ & $\begin{array}{l}\text { Densimetric } \\
\text { Froude no. } \\
\qquad F r_{d}\end{array}$ & $\begin{array}{c}\text { Reynolds } \\
\text { number } \\
\operatorname{Re} \times 10^{3}\end{array}$ & $\begin{array}{l}\text { Bed } \\
\text { roughness } \\
(-)\end{array}$ \\
\hline S1 & 0.023 & 0.0034 & $90-10 \%$ & 0.086 & 0.069 & 0.88 & 5.6 & smooth \\
\hline $\mathrm{S} 2$ & 0.012 & 0.0034 & $90-10 \%$ & 0.063 & 0.081 & 0.65 & 4.8 & smooth \\
\hline S3 & 0.012 & 0.0034 & $0-100 \%$ & 0.074 & 0.069 & 0.82 & 4.8 & smooth \\
\hline S4 & 0.006 & 0.0034 & $90-10 \%$ & 0.072 & 0.087 & 1.10 & 5.9 & smooth \\
\hline S5 & 0.003 & 0.0009 & $90-10 \%$ & 0.022 & 0.047 & 0.59 & 0.98 & smooth \\
\hline S6 & 0.003 & 0.0017 & $90-10 \%$ & 0.043 & 0.061 & 1.01 & 2.5 & smooth \\
\hline S7 & 0.003 & 0.0026 & $90-10 \%$ & 0.060 & 0.085 & 1.47 & 4.8 & smooth \\
\hline S8 & 0.004 & 0.0121 & $90-10 \%$ & 0.084 & 0.185 & 0.99 & 15.0 & smooth \\
\hline S9 & 0.004 & 0.0069 & $90-10 \%$ & 0.074 & 0.160 & 1.08 & 11.0 & smooth \\
\hline S10 & 0.023 & 0.0069 & $90-10 \%$ & 0.106 & 0.093 & 0.91 & 9.3 & smooth \\
\hline S11 & 0.013 & 0.0069 & $90-10 \%$ & 0.106 & 0.091 & 1.07 & 9.1 & smooth \\
\hline S12 & 0.013 & 0.0009 & $90-10 \%$ & 0.043 & 0.036 & 0.69 & 1.5 & smooth \\
\hline $\mathrm{S} 13$ & 0.013 & 0.0017 & $90-10 \%$ & 0.061 & 0.047 & 1.00 & 2.7 & smooth \\
\hline S14 & 0.006 & 0.0069 & $90-10 \%$ & 0.075 & 0.168 & 1.07 & 12.0 & smooth \\
\hline S15 & 0.006 & 0.0009 & $90-10 \%$ & 0.034 & 0.036 & 0.81 & 1.2 & smooth \\
\hline S16 & 0.006 & 0.0017 & $90-10 \%$ & 0.054 & 0.044 & 1.16 & 2.2 & smooth \\
\hline S17 & 0.004 & 0.0034 & $90-10 \%$ & 0.056 & 0.115 & 1.18 & 6.1 & smooth \\
\hline S18 & 0.006 & 0.0026 & $90-10 \%$ & 0.054 & 0.079 & 0.97 & 4.0 & smooth \\
\hline S19 & 0.012 & 0.0026 & $90-10 \%$ & 0.071 & 0.056 & 1.01 & 3.8 & smooth \\
\hline S20 & 0.023 & 0.0026 & $90-10 \%$ & 0.087 & 0.043 & 1.06 & 3.5 & smooth \\
\hline $\mathrm{S} 21$ & 0.023 & 0.0009 & $90-10 \%$ & 0.044 & 0.026 & 0.80 & 1.1 & smooth \\
\hline $\mathrm{S} 22$ & 0.023 & 0.0017 & $90-10 \%$ & 0.059 & 0.042 & 0.75 & 2.3 & smooth \\
\hline $\mathrm{S} 23$ & 0.006 & 0.0034 & $0-100 \%$ & 0.056 & 0.114 & 0.97 & 6.0 & smooth \\
\hline $\mathrm{S} 25$ & 0.006 & 0.0069 & $0-100 \%$ & 0.073 & 0.153 & 1.09 & 11.0 & rough \\
\hline S26 & 0.006 & 0.0034 & $0-100 \%$ & 0.049 & 0.122 & 1.42 & 5.6 & rough \\
\hline S27 & 0.006 & 0.0069 & $0-100 \%$ & 0.061 & 0.167 & 0.87 & 9.6 & rough \\
\hline S28 & 0.006 & 0.0034 & $90-10 \%$ & 0.063 & 0.091 & 1.05 & 5.4 & rough \\
\hline
\end{tabular}

For every experiment the density excess is generated in two different ways depending on the mixture employed. In the case of saline underflows the mixture was obtained by adding salt to clear water, with a small percentage of sediment, added to the mixture as tracer for the UDVP. In the case of turbidity currents the mixture was made by adding only sediments to clear water. Each experiment differs from the others in terms of the nature of the current, salinity or turbidity, the value of the fractional excess density $(\Delta \rho / \rho)$, the flow discharge at the inlet condition $q_{0}$, and bed roughness.

Every UDVP probe employed in the experiments is able to acquire the instantaneous velocity profile along its axis in each section where it is placed. Employing the DOP2000 in multiplexer mode, the system is not able to acquire velocity profiles from every probe simultaneously, but can only acquire in sequence from each probe. As a consequence the time between two consequent profiles at the same cross section is equal to the sum of the recording times of all the probes employed in the experiment.
In any cross section we employ the relations proposed by Ellison and Turner (1959) to evaluate the mean values of velocity $U$ and height $h$ of the current. They read

$$
\begin{gathered}
U h=\int_{0}^{z_{\infty}} u \mathrm{~d} z, \\
U^{2} h=\int_{0}^{z_{\infty}} u^{2} \mathrm{~d} z .
\end{gathered}
$$

The upper limit of integration $z_{\infty}$ is chosen as the height at which $u=0.3 U$. Such choice was motivated by the observation that if that upper limit of integration was employed, then there was a good agreement between the flow thickness computed from the integration of the longitudinal velocity profile and that extracted visually from the lateral sidewall. Different choices, however, would not have led to qualitatively different results. These flow properties were employed to scale the velocity profiles and also to evaluate the flow discharge per unit width $q$ and the buoyancy flux per unit width $B$, defined as 
$q=U h$,

$B=g^{\prime} U h$

The experimental procedure is the same for all the experiments performed. The experiment started when the valve of the flume conduit was opened such to feed the channel with the mixture. At the same time the bottom drain valve placed at the end of the flume was opened an amount such as to remove the same flow discharge from the system and to keep the free surface elevation constant in time and in space during the experiment. We verified that the maximum difference in free surface elevation between the inlet and the outlet was only a few millimeters high. It is also worth mentioning that an overflow drain was present at the downstream end of the flume, in order to prevent the free surface from reaching the top of the sidewalls of the flume. Once the fluid mixture reaches the inlet chamber, which has a sluice gate at the bottom, the current starts flowing on the bed along the channel.

The head of the current starts moving downstream the flume through the first straight reach, proceeds along the bend and continues to the end of the channel. A few minutes after the head of the currents has passed it is possible to observe that the current reaches a quasi-steady state. With quasi-steady flow we mean a flow that is approximately constant in time at a specified cross section. Indeed some small oscillations were present in the flume, hence the prefix quasi. This is the time at which we start measurements of velocity profiles and we take fluid samples to determine the density distribution of the current. Depending on the value of flow discharge, each test had a different duration varying between about 10 and 30 minutes.

In the vast majority of the experiments (23 out of 28) the flow thickness $h$ was less than $12 \mathrm{~cm}$. In five cases (S8, S9, S14, S25 and S27), corresponding to experiments with relatively high flow discharge and low excess density, $h$ was between 15 and $17 \mathrm{~cm}$. We have then computed the relative submergence $\Phi=h / h_{\mathrm{a}}$ with $h_{\mathrm{a}}$ the depth of the ambient fluid. Considering the reference cross section C5 located approximately in the middle of the straight reach, it turned out that the relative submergence ranges between 0.065 and 0.46 . The value of $\Phi$ equal to 0.46 corresponds to experiment $S 8$, while the other four experiments mentioned above have a relative submergence about 0.4 . In all the other experiments the value of $\Phi$ is less than 0.31 . These values are somehow similar to those corresponding to the experiments of Sequeiros et al. (2009) ( $\Phi$ between 0.1 and 0.4) and Britter and Simpson (1978) and Simpson and Britter (1979) ( $\Phi$ between 0.025 and 0.3$)$.

\subsection{Head velocity}

Once the experiment is started, the heavier fluid starts flowing under the ambient fluid. The front of the current is the place where the dense fluid coming from the body meets the still lighter fluid that fills the environment. This is a place of great turbulence, in which the most important phenomena of bed sediment erosion and mixing between the current and the ambient fluid takes place (Allen, 1971; Middleton, 1993).

It is well know that the body of the current is faster than the head (Middleton, 1966a, b; Best et al., 2001). This is confirmed from our experiments as reported in Fig. 2, where we show that the average downstream body velocity is roughly $20 \%$ greater than the head velocity.

Didden and Maxworthy (1982) proposed an empirical expression concerning the value of the head velocity $U_{\mathrm{f}}$ in constant flux gravity currents where the entrainment of ambient fluid is neglected. The authors related the head velocity with the volume flux per unit width $q$ and the reduced gravity $g^{\prime}$ in the form

$U_{\mathrm{f}}=C\left(g^{\prime} q\right)^{1 / 3}$,

with $C$ an order one constant. The value of the constant $C$ was found by Özgökmen and Chassignet (2002), who performed a series of numerical experiments, with a two-dimensional $(x, z)$ nonhydrostatic model, yielding the value $C=1.05 \pm 0.1$. The relation proposed above is confirmed by our experimental results: in Fig. 3 the theoretical prediction (Eq. 5) is compared with the experimental velocity measured during our experiments. The theoretical prediction tends to slightly overestimate the experimental values of front velocity.

\section{Observations on the structure of velocity and concentration profiles and global flow properties}

\subsection{Velocity profiles}

The velocity profiles were computed averaging from 30 up to 120 instantaneous velocity profiles. Depending on the acquisition mode employed of the UDVP, the time windows where velocity was averaged varied between 5 and $15 \mathrm{~min}$.

Figure 4 shows a typical example of the longitudinal velocity profile, once the time averaging operation has already been performed. The interface between the current and the clear water is located roughly $9 \mathrm{~cm}$ above the rigid bed. Moving up from the bottom we can notice that the velocity rapidly increases reaching the maximum located in the lower part of the current. Above the peak, the velocity invariably decreases approaching the current interface. Above the interface there is still a small layer of ambient fluid that is dragged downstream by the underlying current, whereas above such fluid layer, a back flow is typically observed characterized by velocities much smaller than the underlying current.

The vertical structure of longitudinal velocity is not the same in the longitudinal direction. This is shown in Fig. 5a where we report a sequence of longitudinal velocity profiles evidencing the spatial development of the average velocity profiles in a typical saline current (experiment S4: $q_{0}=0.0034 \mathrm{~m}^{2} \mathrm{~s}^{-1}, \Delta \rho / \rho=0.6 \%$ ). Starting from the inlet, 


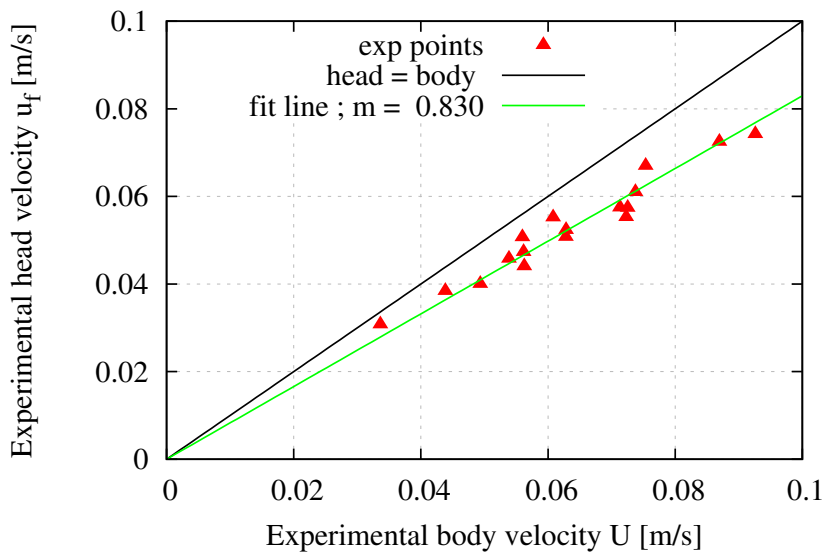

Figure 2. Comparison between the value of the experimental head velocity and the value of the velocity of the body averaged in time.

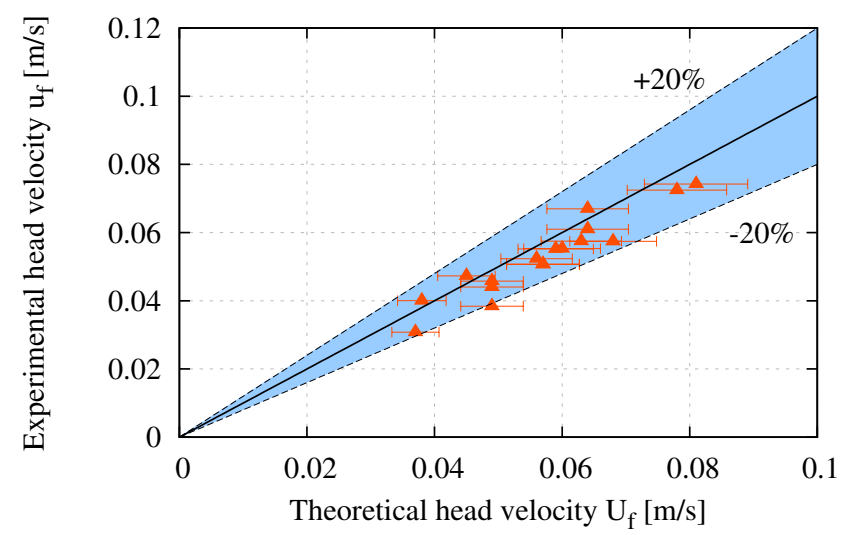

Figure 3. Comparison between the experimental values and the theoretical predictions obtained by the empirical expression proposed by Didden and Maxworthy (1982) with $C=1.05$.

where the shape of velocity profile is jet-like, the profiles attain a similar vertical distribution proceeding downstream where the flow is quasi-uniform (Fig. 5b). Unfortunately the DOP was not able to measure the velocity profile in the region close to the sluice gate where the flow was supercritical. The cross section $\mathrm{C} 1$ closest to the inlet was already located in the region downstream from the inlet where the flow was already quasi-uniform. Every run has a similar behavior, despite the flow thickness and velocity intensity change in different experiments.

The light blue line in Fig. 5 represents the interface between the current and the ambient fluid observed during the experiment. This was extracted by visually identifying the interface between the clear water and the turbid underflow. It is possible to observe that the interface is almost parallel to the bottom slope, thus suggesting that the current reaches a quasi-uniform condition quite close to the inlet. The blue dots are the values of the flow height $h$ obtained by the averaged velocity profile, using Eqs. (1) and (2); it is possible to notice

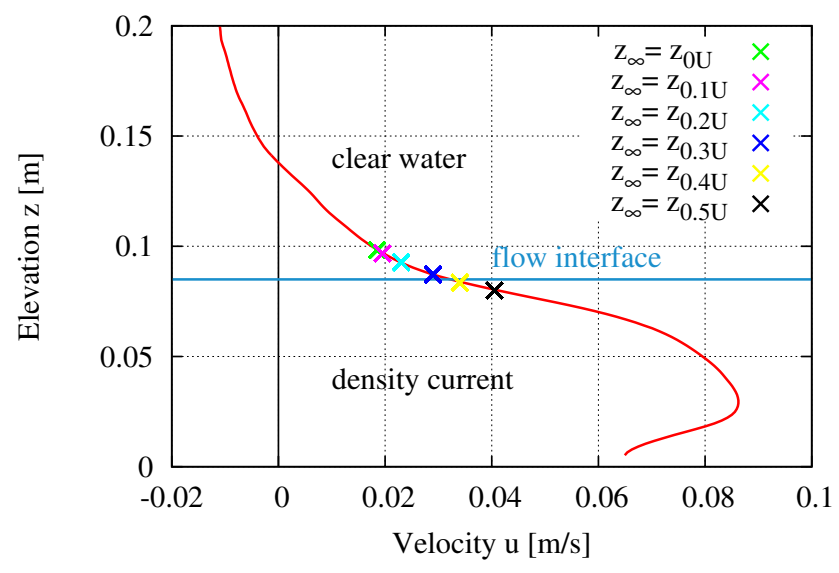

Figure 4. Comparison between the flow height computed integrating the longitudinal velocity profile (red line) with different upper limits of integration $(0-0.1-0.2-0.3-0.4-0.5 U)$ and the flow interface extracted visually (blue line) from the lateral sidewall (experiment S4 - section C5). The crosses are located at heights corresponding to the flow thickness computed employing different values of the upper bound of integration.

the good correspondence between the elevation of flow interface computed from velocity profiles and that measured visually during the experiment. It is worth noting, however, that the blue dots in the initial four profiles are consistently below the flow interface extracted visually during the experiments, whereas the agreement between line and dots improves significantly in other profiles. Such particular behavior is likely due both to the influence of the inlet condition on the distribution of longitudinal flow velocity in the first portion of the flume and to the presence of the hydraulic jump. Not considering the profile close to the inlet and upstream from the hydraulic jump, in Fig. 6a the velocity profiles at different cross sections are compared. It is evident that the velocity changes only slightly proceeding downstream.

From the data acquired during each test it is possible to find out some average characteristics of the currents obtained some distance ahead from the flume inlet. Indeed, the flow is supercritical at the upstream cross section, but becomes quasi-uniform downstream the hydraulic jump forming a short distance from the flow entrance. In particular, from Table 1 it can be noticed that the densimetric Froude number $F r_{\mathrm{d}}=U / \sqrt{g^{\prime} h}$, with $g^{\prime}=g \Delta \rho / \rho$ representing the reduced gravity calculated in the reference cross section C5, remains supercritical in many cases, but is less than unity in some other cases.

Time averaged velocity profiles have been calculated in every measuring cross section. Both the longitudinal velocity and the vertical coordinate were then scaled employing the values of depth averaged velocity and flow thickness corresponding to Eqs. (1) and (2) in order to obtain dimensionless velocity profiles. It is evident from Fig. $6 \mathrm{~b}$ that, neglecting the profile too close to the inflow condition, velocity profiles 

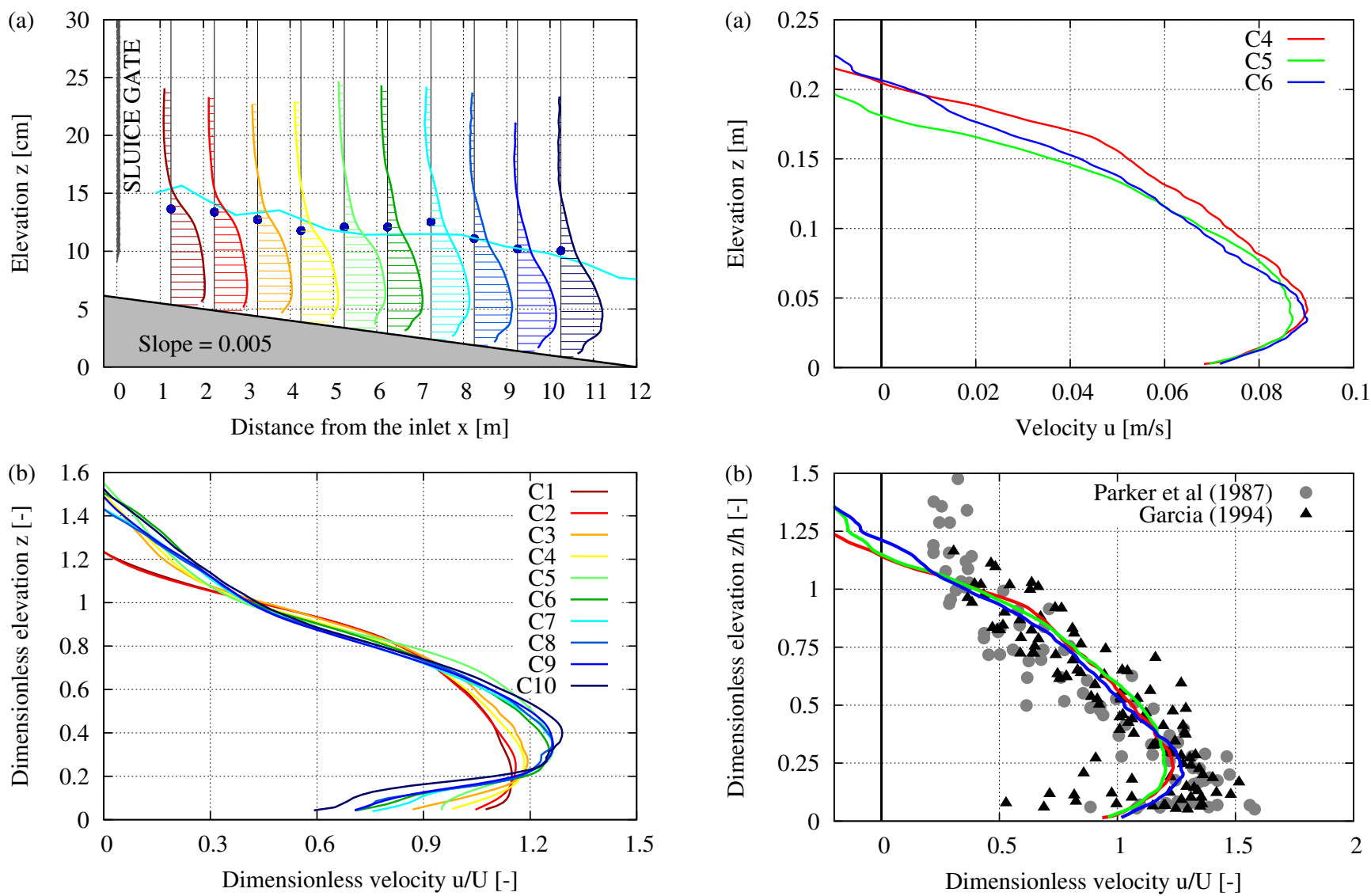

Figure 5. Velocity profiles measured in experiment $\mathrm{S} 4$ (saline flow, $q_{0}=0.0034 \mathrm{~m}^{2} \mathrm{~s}^{-1}, \Delta \rho / \rho=0.6 \%$ ). (a) Spatial distribution of longitudinal velocity and flow interface (blue line) measured during the experiment. The interface height obtained from the corresponding velocity profile (blue dots) employing Eqs. (1) and (2) is also reported. (b) Dimensionless velocity profiles.

corresponding to the same experiment, once made dimensionless, tend to collapse on a narrow band. Far from the initial section where the flow structure is determined by inflow condition and by the eventual presence of a hydraulic jump, the flow adjusts to a quasi-uniform flow characterized by the existence of a self-similar velocity profile on the vertical. In Fig. $6 \mathrm{~b}$ we have also reported the points corresponding to the experimental observations of supercritical currents of Parker et al. (1987) and both supercritical and subcritical currents of Garcia (1994) that bracket our results within the body of the current, in spite of the quite low longitudinal bed slope of our experiment $(S=0.005)$, much smaller than that corresponding to the above mentioned experiments $(S=0.05$ and $S=0.08$, respectively). In the following we will consider the vertical profiles measured along the channel axis and corresponding to cross section C5 located $5.25 \mathrm{~m}$ from the upstream inflow where the flow is fully developed and has attained a quasi-uniform configuration.

Figure 6. Example of velocity profiles: (a) dimensional velocity profiles and (b) dimensionless velocity profiles in different cross sections from experiment S25 $\left(q_{0}=0.0069 \mathrm{~m}^{2} \mathrm{~s}^{-1} ; \Delta \rho / \rho=0.6 \%\right)$. The points corresponding to the experimental observations of supercritical currents of Parker et al. (1987) and both supercritical and subcritical currents of Garcia (1994) are also reported.

\subsection{Flow discharge and water entrainment}

From the calculation of the depth averaged velocity $U$ and flow thickness $h$ of the currents we calculated the flow discharge per unit width, $q=U h$, in every cross section where velocity measurements were performed. It is possible to notice in Fig. 7 that, downstream from the hydraulic jump located close to the inlet, the current adjusts its characteristics to a quasi-steady condition where flow discharge slightly increases downstream due to entrainment of clear water from above. Such increase in flow discharge is also reflected in a slight thickening of the current proceeding downstream, whereas flow velocity $U$ tends to keep almost constant.

From the calculation of the flow discharge in the downstream direction it is possible to notice that, as expected, all the experiments show a value of $q$ greater than the inlet value. This is related to water entrainment from above, particularly intense in the first few meters after the supercritical inlet condition, where a hydraulic jump was in some experiments present. Water entrainment from above was however 


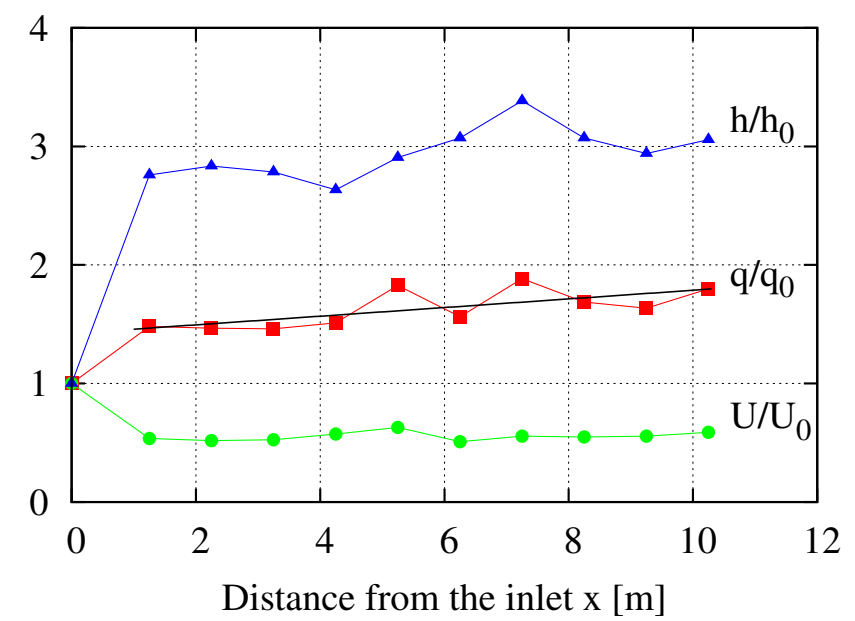

Figure 7. Experiment S4: spatial development of the mean velocity, mean height and flow discharge of the current, compared with their initial value.

different in the various experiments performed, highly dependent on the initial value $q_{0}$ imposed upstream. In particular, series characterized by low values of $q_{0}$ maintain the flow discharge approximately constant along the flume, whereas the increase of flow discharge $q$ proceeding downstream was more intense in those experiments with high values of $q_{0}$ at the inlet. This is related to the character of the current, more prone to entrain fresh water as the flow becomes more supercritical.

In Parker et al. (1987) the authors suggest a relation (their Eq. 20) to estimate the entrainment coefficient that reads

$e_{\mathrm{w}}=\frac{0.075}{\left(1+718 R i^{2.4}\right)^{0.5}}$.

Such equation has been used employing the values of the Richardson number averaged over the straight reach. The values of $e_{\mathrm{w}}$ obtained from Eq. (6) have been compared with the experimental value of the entrainment coefficient $\tilde{e}_{\mathrm{w}}$ obtained calculating the average variation of flow discharge along the same straight reach. The comparison reported in Fig. 8 shows that the empirical prediction of Parker et al. (1987) provides a good estimate of water entrainment.

\subsection{Density profiles}

Density profiles are obtained from the measurements performed on the flow samples taken by the siphons. Each measure taken at different heights from the bottom provides the time averaged value of fluid density at that elevation: indeed every sample has a density value that is the mean temporal value on a time frame necessary to fill the sample. Each sample takes about $10 \mathrm{~min}$ to be collected, and the ten siphons work simultaneously.

In Fig. 9a we show a comparison between the density profiles measured in the same cross section in four experiments

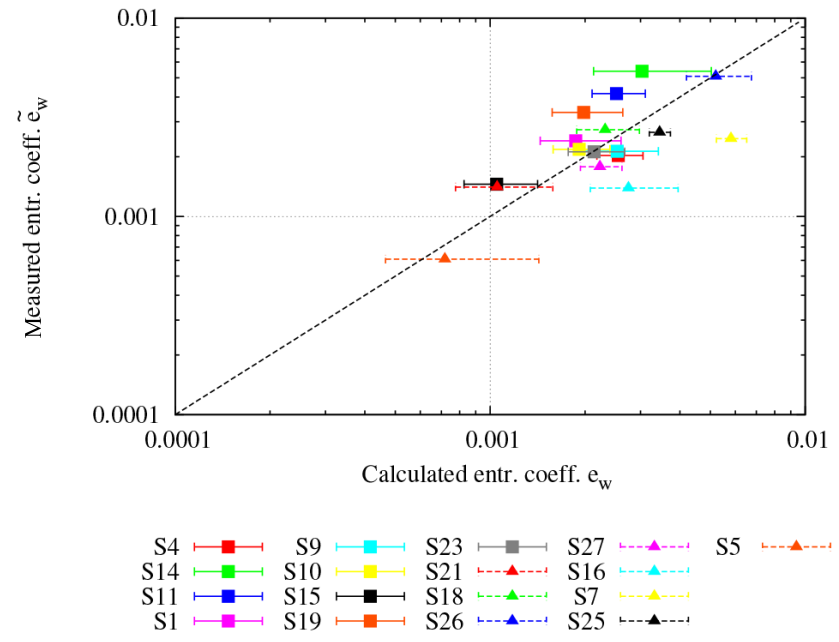

Figure 8. Comparison between the experimental value of the entrainment (entr.) coefficient $\tilde{e}_{\mathrm{w}}$ obtained calculating the average variation of flow discharge along the straight reach and the calculated value $e_{\mathrm{w}}$ obtained from Eq. (6). The horizontal bars represent the root mean square deviation associated with the spatial variability of the densimetric Froude number.

of saline currents characterized by the same upstream discharge $\left(q_{0}=0.0026 \mathrm{~m}^{2} \mathrm{~s}^{-1}\right)$ but different values of the excess density at the inlet. It can be immediately noticed that the maximum value of the excess density differs from the corresponding inlet condition. This is primarily due the strong mixing effect occurring close to the flow inlet in correspondence of the hydraulic jump and secondly to the water entrainment of ambient fluid downstream of the hydraulic jump where the current has attained a quasi-uniform configuration. Though the entrainment has a secondary role compared with the mixing effects in the region close to the input section, it is responsible for current dilution in the downstream direction. The density distribution along the vertical, in all the experiments performed, has a similar structure: it is approximately constant in the dense current, and rapidly decreases in the region near the interface to reach the value equal to the ambient fluid further up along the vertical.

This if further demonstrated in Fig. $9 b$ and c, where the profiles of excess density are scaled with their corresponding depth averaged value $\overline{\Delta \rho}$ and vertical distances are scaled with flow thickness. The averaged excess density was computed from the definition of buoyancy flux per unit width:

$U g \frac{\overline{\Delta \rho}}{\rho} h=g \int_{0}^{z_{\infty}} u \frac{\Delta \rho}{\rho}(z) \mathrm{d} z$.

The upper limit of integration was set equal to that employed to compute the depth averaged velocity and flow thickness (i.e., the height at which $u$ is equal to $0.3 U$ ). Note that the vertical segments of the profiles are related to the precision of the density hydrometer, which is equal to $0.5 \mathrm{~kg} \mathrm{~m}^{-3}$. 


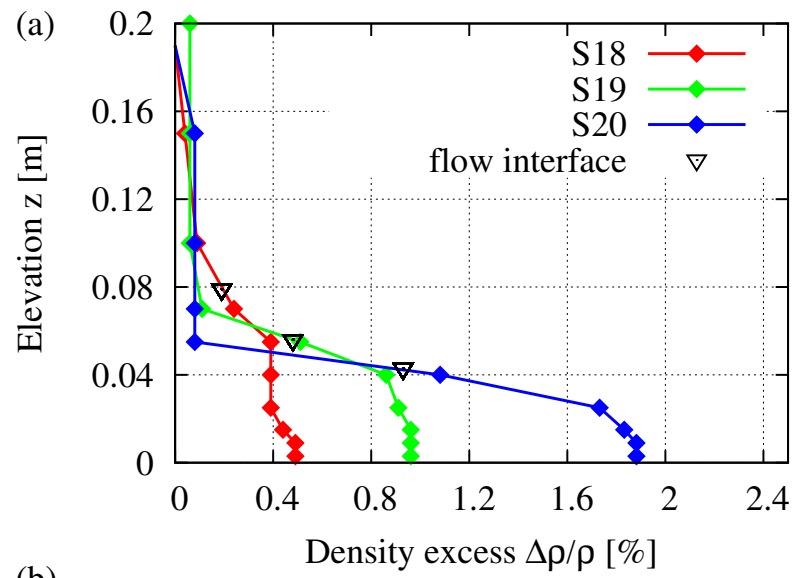

(b)

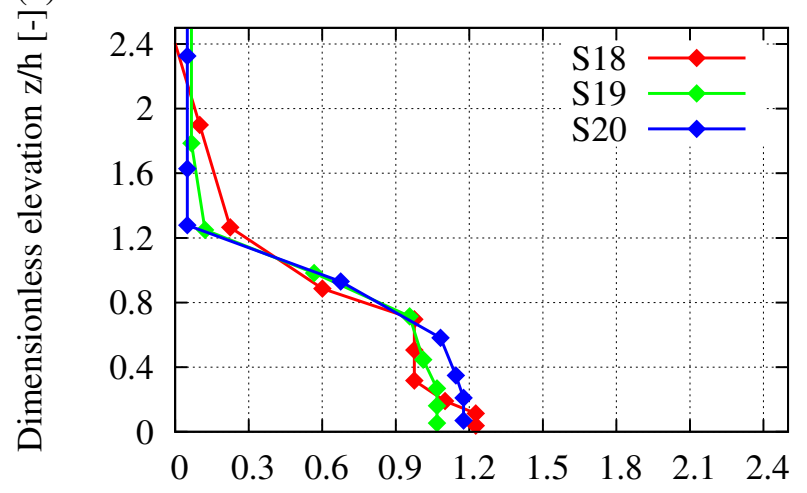

Dimensionless density excess $\Delta \rho / \Delta \rho_{\text {mean }}[-]$

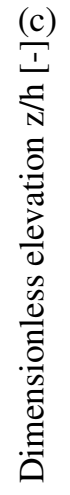

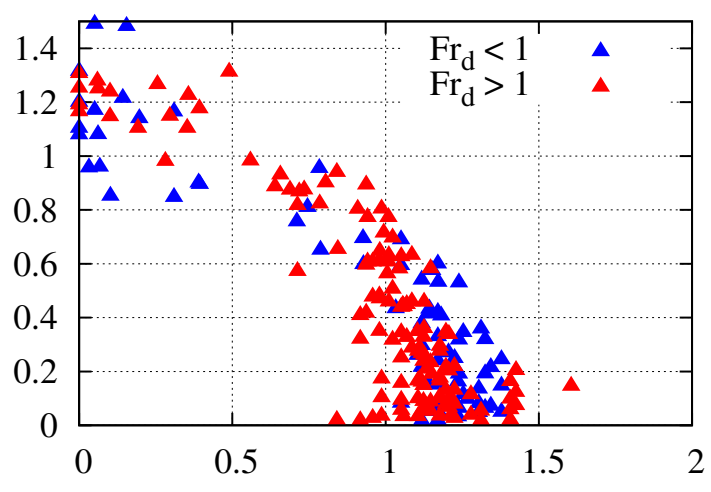

Dimensionless density excess $\Delta \rho / \Delta \rho_{\text {mean }}[-]$

Figure 9. (a) Dimensional and (b) dimensionless density profiles measured in cross section $\mathrm{C} 5$ in experiments with different values of the inlet excess density, and the same value of flow discharge $q_{0}=0.0017 \mathrm{~m}^{2} \mathrm{~s}^{-1}$. The black triangles indicate the flow interface level of each current. (c) Similarity plot of dimensionless density profiles measured in all the experiments performed (both saline and turbidity currents) and classified in terms of the densimetric Froude number.

Even if the initial value of the density at the inlet section changes, dimensionless profiles collapse on each other (Fig. 9b). Indeed, in the case of density currents density strat- ification on the vertical within the current is nearly absent. The excess density distribution of our experiments is comparable to that obtained from Sequeiros et al. (2010) in the case of subcritical flows, with a minor difference close to the interface where the density profiles are more stratified in our experiments than those obtained by Sequeiros et al. (2010) characterized by a more abrupt decrease in excess density. On the contrary, we did not observe notable differences in the case of normalized density profiles in supercritical currents (Fig. 9c) that are still uniformly distributed inside the current, whereas in the work of Sequeiros et al. (2010) the profiles are more stratified, showing a relative excess density maximum near the bed and a minimum in the upper half of the current. This difference may be related to the fact that in our experiments we covered a smaller range of supercritical flows (maximum densimetric Froude number=1.47).

Conversely, if one observes Fig. 10, which presents a comparison between the profile of excess density of a saline current and the corresponding profile of a turbidity current, we can see that the latter has a higher density in the lower part, while it decreases gradually towards the interface. In fact, in the upper part of the profile the saline flow has a higher density value. This fact is due to the presence of suspended sediments inside turbidity currents, which tend to settle and move the higher value of the density profile towards the bottom. In the experiments performed the sediments were very fine $\left(d_{\mathrm{s}}=50 \mu \mathrm{m}\right)$, which could be the reason why this tendency is not very clear. Also, it is worth pointing out that the samples taken with the syphons are affected by a measuring error larger than the differences in excess density that we would like to detect with the present comparison.

\section{Velocity profiles under quasi-uniform conditions}

Our attention is here focused on the quasi-steady conditions attained by the current some time after the passage of the current head. As already pointed out the body of the current is characterized by a quasi-uniform flow condition. Velocity measurements are recorded during the whole duration of each experiment, including the head. However, here we just consider velocity measurements corresponding to the body of the current. Similarly, density measurements are sampled in the body of the current.

\subsection{Effect of the Reynolds number}

One of the crucial parameters affecting the structure of the current is the Reynolds number of the current. To quantify its effects on the velocity profile we varied flow discharge at the inlet. Indeed the Reynolds number $R e$ is proportional to the specific flow rate $q$ in the form

$R e=\frac{U h}{v}=\frac{q}{v}$, 


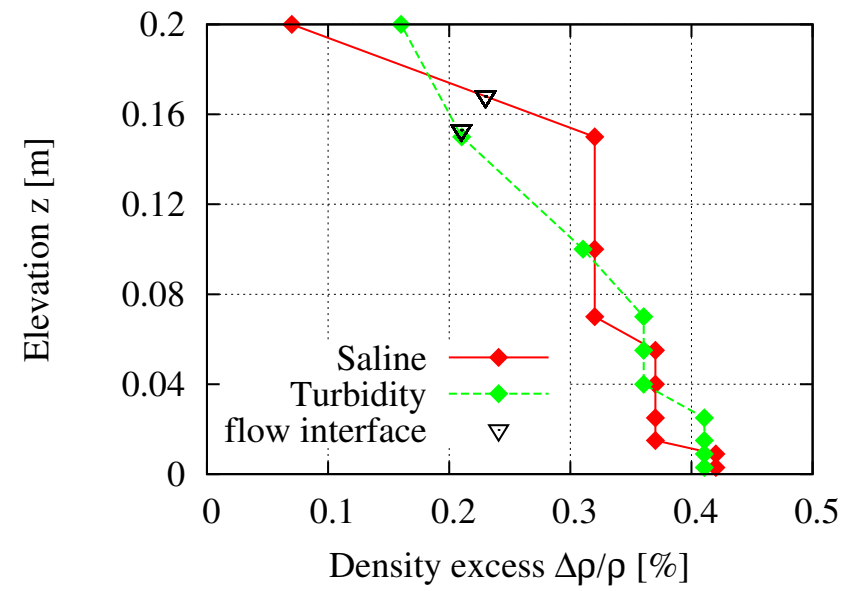

Figure 10. Density profiles: comparison between a saline current (experiment S14) and a turbidity current (experiment S25), measured in cross section $\mathrm{C} 5$. The black triangles indicate the flow interface level of each current.

where $v$ is the kinematic viscosity of the fluid and $U$ and $h$ are respectively the average velocity and height of the currents, calculated in the cross section from the longitudinal velocity profile.

We show in Fig. 11a the vertical profiles of different saline experiments performed by keeping the value of the excess density at the inlet constant and equal to $0.3 \%$. It is evident that increasing the flow rate the velocity intensity increases and simultaneously the current becomes thicker. The increase of velocity, flow thickness and elevation of velocity peak, as a consequence of increasing inlet flow discharge is an expected result that has already been observed (e.g., Sequeiros et al., 2010). However from this graph it is not possible to derive some common characteristics; differences and analogies are more clearly evidenced if we scale all velocity profiles measured in the fully developed region with their characteristic values of velocity $U$ and flow thickness $h$. They are reported in Fig. 11b, with colors corresponding to different experiments; furthermore, the series have been indicated according to the Reynolds number of the current. In Fig. $11 \mathrm{~b}$ it is possible to distinguish two different shapes of the velocity profiles. In particular, currents characterized by a low value of the Reynolds number (red and green lines) exhibit a velocity maximum related to their averaged value higher than the series with higher value of $R e$. As a direct consequence the former shape results to be sharper than the latter.

It is also possible to observe that there is a difference in the part of the velocity profiles up to the peak; in particular, the concavity is upwards for low $R e$ and opposite in the other case. Moreover, the part of the external ambient fluid that follows the flow in the downstream direction, compared to the thickness of the current itself, increases with decreasing value of the Reynolds number of the flow. Similar results were recently found in the framework of direct numerical

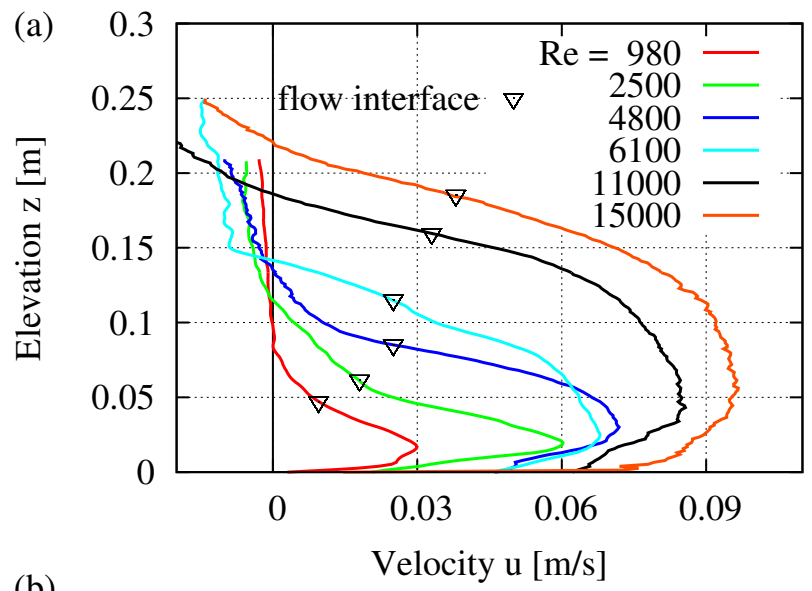

(b)

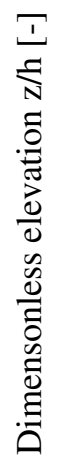

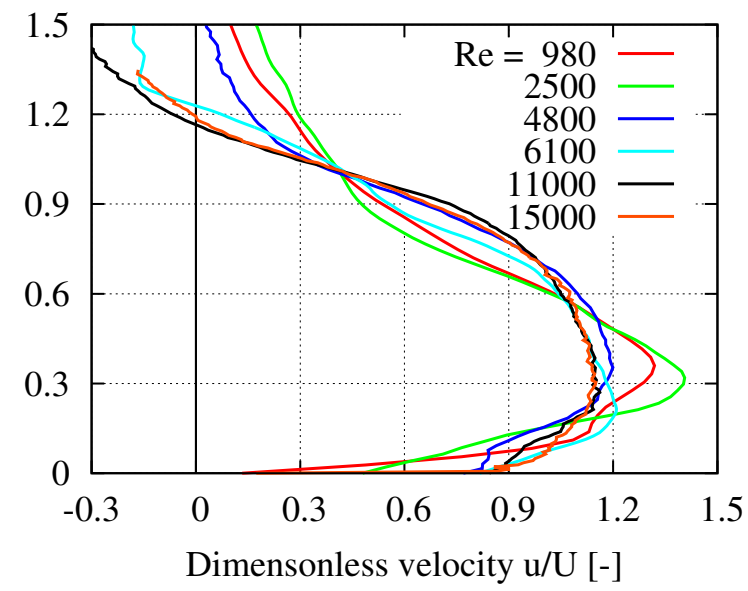

Figure 11. Dimensional (a) and dimensionless (b) averaged velocity profiles: effects of the variation of the flow rate $q$; saline currents with $\Delta \rho / \rho=0.3 \%$ measured in cross section C5 (experiments S5, S6, S7, S17, S9 and S8). The black triangles indicate the flow interface level of each current.

simulations (DNS) of sediment-laden channel flows (Cantero et al., 2009). In this case the authors observed that the presence of suspended sediments induces a self-stratification that damps the turbulence and can either lead to a reduction of turbulence or to a complete relaminarization of the flow in a region near the bottom wall. In both cases a gradual deviation of the velocity maxima toward the bottom wall with increasing values of sediment concentration was obtained.

\subsection{Effect of the presence of suspended sediments}

Although the fuel that induces and sustains these kinds of phenomena is the difference in density between the flow and the ambient fluid, density currents show a different behavior whether they are induced by the presence of dissolved salt or suspended sediment. The reason for this difference is related to two aspects. The first is due to the well known effect of suspended sediments on turbulence dumping. Indeed, in a classical paper of open channel flows, Vanoni (1946) documented 
experimentally that an increase in the mean concentration of suspended sediment was associated with an increasing velocity gradient at the wall. It was first hypothesized and then confirmed by theoretical investigations (Villaret and Trowbridge, 1991; Herrmann and Madsen, 2007; Bolla Pittaluga, 2011), experimental observations (Muste et al., 2009) and numerical simulations (Cantero et al., 2009) that the latter effect might originate from suspended sediments damping turbulence and decreasing turbulent mixing. The second reason is related to sediment entrainment from the bed. Both saline and turbidity currents can indeed modify their density entraining ambient fluid that dilutes them from above. In the case of sediment laden currents, however, the flow can also exchange sediments with the erodible bed either decreasing bulk density through sediment deposition or, vice versa, increasing bulk density through erosion from the bed of the submarine canyon.

Figure 12 shows the difference in the velocity profile between a saline (S14 red line) and a turbidity (S25 green line) current in two experiments performed under the same conditions with the exception of the way the same value of excess density was generated (salt or sediments). It can be immediately noticed that the shape of the two dimensionless profiles show some significant differences. Sediment laden flows have an higher value of velocity, compared with the averaged one, that is located closer to the bed; as a consequence the velocity profile appears quite sharp at the velocity peak. On the contrary, the flow speed of the saline current is more spread on the vertical, resulting in a flatter velocity distribution characterized by a lower value of peak velocity compared to the previous case. Finally, in the case of the turbidity current, velocity gradually decreases with distance from the interface whereas the velocity gradient is much more abrupt in the case of the saline current. Sequeiros et al. (2010), from comparing their experimental results with different data sets, come to a similar conclusion that the average height of peak velocity for turbidity currents is lower than for saline flows.

\subsection{Effect of bed roughness}

We also investigated the effects of the presence of a rough bed on the velocity distribution. Most of the experiments performed were carried out on a smooth plane bed. We then performed a new set of experiments placing a uniform layer of fine gravel, characterized by a $d_{50}=3 \mathrm{~mm}$, on the smooth fixed bed. The sediment size was chosen sufficiently rough such that particles remained fixed during the flow event.

Results are shown in Fig. 13 where we compare two classes of density currents performed under the same excess density at the inlet $\left(\Delta \rho / \rho_{0}=0.6 \%\right)$, similar values of flow discharge at the inlet $\left(q_{0}=0.0034-0.0069 \mathrm{~m}^{2} \mathrm{~s}^{-1}\right)$ but over a smooth (experiments S4, S23 and S25) and a rough bed (experiments S26, S27 and S28), respectively.

We first noticed (not shown) that differences in velocity profiles between the two cases were evident. Primarily the

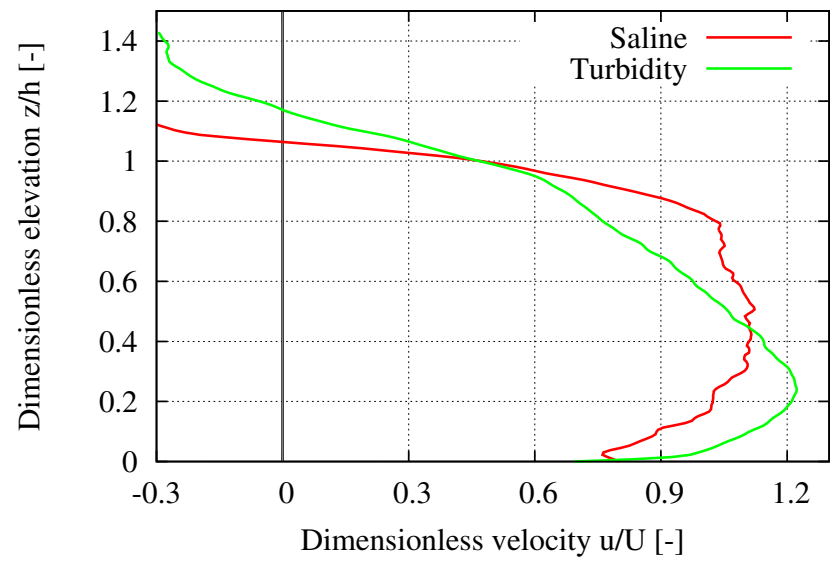

Figure 12. Comparison between a saline density current (experiment S14) and a turbidity current (experiment S25) with suspended sediment performed under the same conditions $\left(q_{0}=0.0069 \mathrm{~m}^{2} \mathrm{~s}^{-1}\right.$ and $\Delta \rho / \rho_{0}=0.6 \%$ ), measured in cross section C5.

maximum speed of the current was greater and located closer to the bed in the smooth configuration with respect to the rough case. The velocity intensity at the bottom was reduced as a result of increased bed friction; in addition the velocity profile increased its thickness.

Observing Fig. 13 it is interesting to note that the dimensionless longitudinal velocity is characterized by a velocity peak that is higher in the rough bed experiment with respect to the smooth one. Indeed, the height of the velocity peak moves from roughly $0.25 h$ in the smooth case to roughly $0.4 h$ in the rough case. Also, the dimensionless flow velocity is slightly reduced in the lower part close to the bed, as a consequence of the increase in bed resistance, and is slightly faster above the velocity peak. It is also worth noting that the two profiles show the same value of the maximum dimensionless velocity $\left(u_{\max } / U\right)$ and that the elevation of the interface is not affected significantly by the change in bed roughness. Such scenario is consistent to that originally found by Sequeiros et al. (2010) on higher longitudinal bed slopes.

\subsection{Effect of excess density}

Another aspect that we wanted to investigate is the effect of the value of the excess density on the velocity profile. We then performed three saline experiments generating currents characterized by different values of excess density and keeping all the other input values constant. Figure 14a shows that, increasing the value of excess density, the flow increases its peak velocity and also the depth averaged velocity, and at the same time becomes thinner with a velocity peak closer to the bottom. Again such results are consistent to those found by Sequeiros et al. (2010) on higher longitudinal bed slopes.

Although the effect that an increase in density has on the current is evident (Fig. 14a), observing the dimensionless profiles in Fig. 14b, the shape of the velocity profile does 


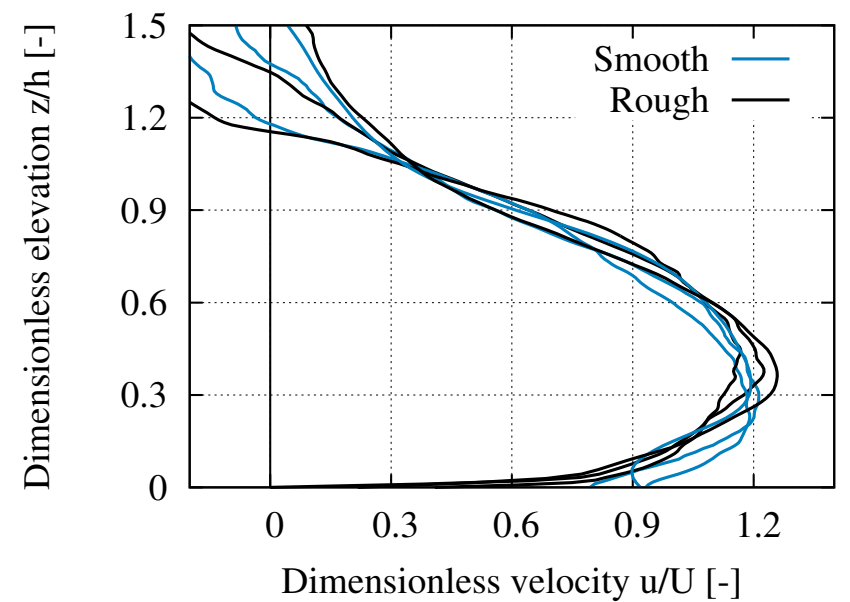

Figure 13. Comparison between density currents flowing over a smooth (experiments S4, S23 and S25) and rough (experiments S26, S27 and S28) bed. All the profiles refer to cross section C5 located in the middle of the straight reach.

not seem to be affected by this change. It should be noted however that the variations of excess density are small, as they are limited to a few percent. They are then sufficient to influence the overall flow dynamics of the current but the values of excess density are not large enough to produce significant changes on the dimensionless shape of longitudinal velocity. This suggests that the excess density is, among the parameters here considered and in the range of variation here employed, the one that has a smaller influence on the shape of the longitudinal velocity profiles. Actually, a moderate influence of the subcritical or supercritical character of the current on the similarity density profiles was found by Sequeiros et al. (2010), who pointed out that the fractional excess density varies more strongly near the bed in supercritical flow. The accuracy of our velocity measurements near the bed might have obscured to us such weak effect.

\subsection{Effect of the densimetric Froude number}

Finally, we investigate the influence of the densimetric Froude number $F r_{\mathrm{d}}$ on the velocity profile. We selected the experiments characterized by different values of $F r_{\mathrm{d}}$, but with similar characteristics of the other parameters examined before. In particular, they have a value of $R e$ larger than $4.8 \times 10^{3}$ up to a maximum of $15 \times 10^{3}$, and they are all saline currents flowing on a smooth bed. The experiments considered here have a value of $F r_{\mathrm{d}}$ falling in the range of $0.65-0.88$ for the subcritical flows, and in the range of $1.07-1.18$ for the supercritical cases. As it can be seen in Fig. 15, the dimensionless profiles of velocity do not show an evident difference related to the character of the current (subcritical or supercritical). According to the present experimental observations, the densimetric Froude number does not affect significantly the dimensionless shape of the velocity profile inside the cur-

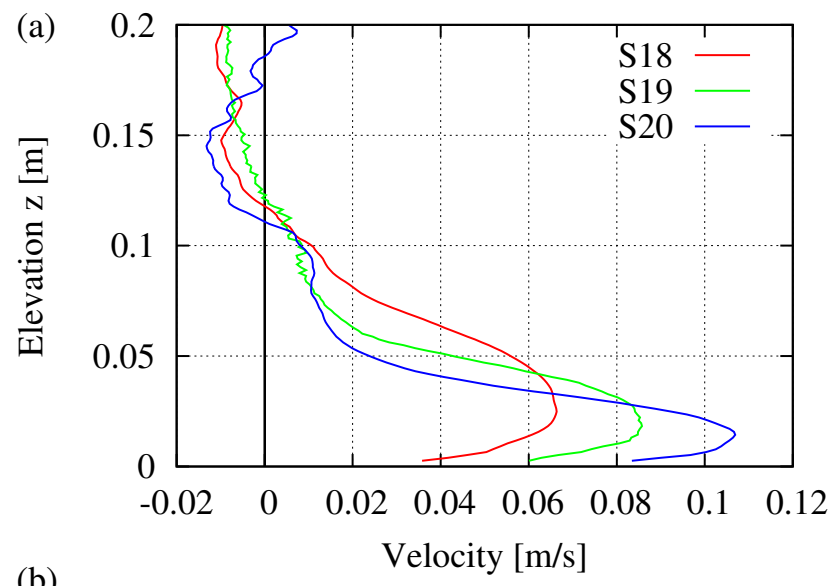

(b)

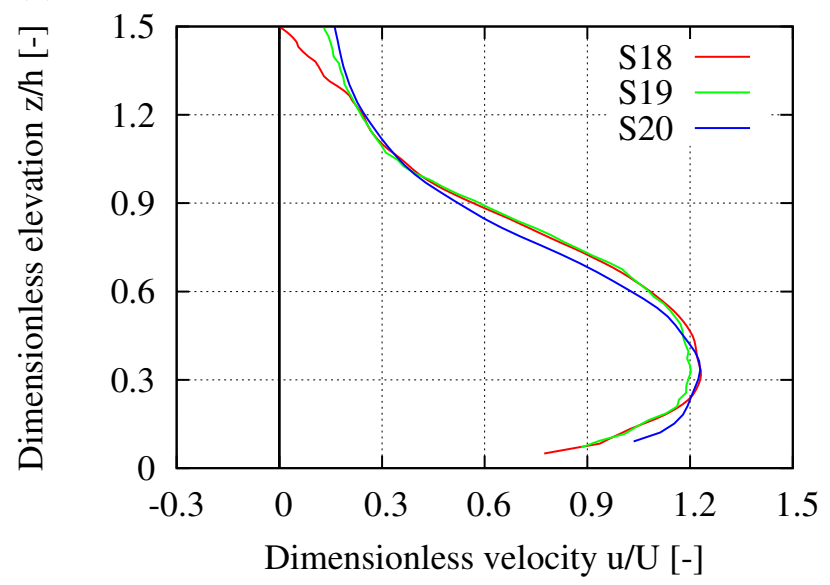

Figure 14. Dimensional (a) and dimensionless (b) comparison between density current velocity profiles with different density excess $(\Delta \rho / \rho)$ and same flow discharge $\left(q_{0}=0.0026 \mathrm{~m}^{2} \mathrm{~s}^{-1}\right)$ at the inlet (experiments S18, S19 and S20). The profiles are measured in cross section C5.

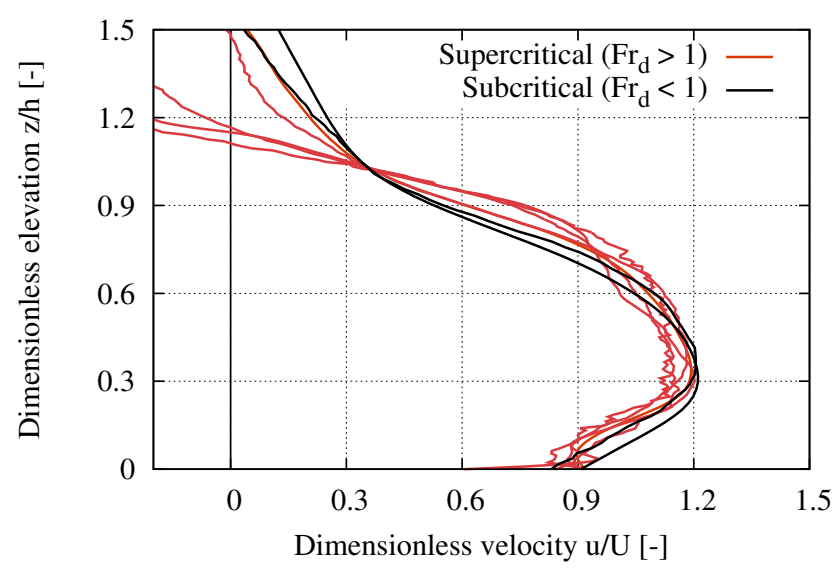

Figure 15. Comparison between subcritical $\left(F r_{\mathrm{d}}<1\right)$ and supercritical $\left(F r_{\mathrm{d}}>1\right)$ experiments.

rent body. However significant differences arise in the velocity profile above the flow interface. Indeed, flows with low 
values of $F r_{\mathrm{d}}$ show a slower transition of the velocity profile from the current to the ambient fluid, while the currents with high $F r_{\mathrm{d}}$ are characterized by dimensionless velocity profiles that abruptly decrease near the flow interface. This behavior could be useful to understand the mixing processes at the interface and consequently could play a key role in understanding water entrainment.

It is also worth point out that the independence of the densimetric Froude number of the dimensionless velocity profile is a new and unexpected result. In fact, in the literature there has been a general consensus on the notable differences between subcritical and supercritical flows (e.g., Garcia, 1994; Sequeiros et al., 2010). It has been observed that in the former case the peak velocity is lowest and located farthest above the bed, whereas in the latter case it is highest and located closest to the bed. Only recently, Bolla Pittaluga and Imran (2014), in the framework of a theoretical model, found that the influence of the densimetric Froude number on the vertical profiles of velocity and concentration is felt only if stratification effects, induced by the concentration gradient that leads to damping of turbulence, are accounted for. On the contrary, they found that if stratification effects are neglected, the densimetric Froude number does not affect the vertical profiles. More investigations are then needed to further clarify this point.

\section{Conclusions}

In this work we reported the results of 27 experiments on turbidity and saline density currents. Every experiment was performed by changing either the value of flow discharge $\left(q_{0}\right)$ at the inlet, the fractional excess density $(\Delta \rho / \rho)$ at the inlet, the way in which the excess density was generated (with salt or sediments) or, finally, the roughness of the bed. We were interested in quantifying how these parameters affect the dynamics of the current flowing in a straight channel, and if it was possible to identify some dimensionless parameter responsible for the vertical shape of the dimensionless longitudinal velocity. Indeed, we focused our attention on the development of the currents in the first straight reach of our flume, where we observed the achievement of a quasiuniform state of the current characterized by self-similar dimensionless velocity profiles. These turned out to be affected by the Reynolds number of the flow, by the relative bed roughness and by the presence of sediment in suspension. The densimetric Froude number, apparently, turned out to have a negligible effect on the vertical structure of the dimensionless velocity profile. More specifically, currents with low values of the Reynolds number were characterized by sharper profiles close to the peak velocity with respect to those corresponding to large values of the Reynolds number. The presence of suspended sediment in the currents, which distinguish turbidity from saline currents, was responsible for the downward movement of the peak velocity; this was due to the natural property of the sediments to settle down. On the contrary, increasing the bed roughness we observed that the peak velocity was higher that in the case of a smooth bed.

We are presently extending the measurements to the curved bend, located downstream from the first straight reach in order to investigate the vertical structure of secondary flow in currents flowing in a constant curvature bend, and their possible influence on the structure of longitudinal velocity as well as on the overall dynamics of the current.

Acknowledgements. Partial funding provided by the University of Genova within the project Morphodynamics of turbidity currents flowing in submarine meandering channels (Progetto di Ateneo, 2011) and by Shell International Exploration and Production is gratefully acknowledged. This work is also part of the Ph.D. Thesis of M. Stagnaro to be submitted to the University of Genova in partial fulfillment of his degree.

Edited by: F. Metivier

\section{References}

Allen, J. R. L.: Mixing at turbidity current heads, and its geological implications, J. Sediment. Res., 41, 97-113, 1971.

Altinakar, M., Graf, W., and Hopfinger, E.: Weakly depositing turbidity current on a small slope, J. Hydraul. Res., 28, 55-80, 1996a.

Altinakar, M., Graf, W., and Hopfinger, E.: Flow structure in turbidity currents, J. Hydraul. Res., 34, 713-718, 1996b.

Best, J. L., Kirkbride, A. D., and Peakall, J.: Mean Flow and Turbulence Structure of Sediment-Laden Gravity Currents: New Insights using Ultrasonic Doppler Velocity Profiling, 157-172, Blackwell Publishing Ltd., 2001.

Bolla Pittaluga, M.: Stratification effects on flow and bed topography in straight and curved erodible streams, J. Geophys. Res., 116, F03026, doi:10.1029/2011JF001979, 2011.

Bolla Pittaluga, M. and Imran, J.: A simple model for vertical profiles of velocity and suspended sediment concentration in straight and curved submarine channels, J. Geophys. Res.-Earth, 119, in press, doi:10.1002/2013JF002812, 2014.

Britter, R. and Simpson, J.: Experiments on the dynamics of a gravity current head, J. Fluid Mech., 88, 223-240, 1978.

Cantero, M. I., Balachandar, S., Cantelli, A., Pirmez, C., and Parker, G.: Turbidity current with a roof: Direct numerical simulation of self-stratified turbulent channel flow driven by suspended sediment, J. Geophys. Res.-Oceans, 114, C03008, doi:10.1029/2008JC004978, 2009.

Didden, N. and Maxworthy, T.: The viscous spreading of plane and axisymmetric gravity currents, J. Fluid Mech., 121, 27-42, 1982.

Ellison, T. H. and Turner, J. S.: Turbulent entrainment in stratified flows, J. Fluid Mech., 6, 423-448, 1959.

Garcia, M. and Parker, G.: Experiments on the entrainment of sediment into suspension by a dense bottom current, J. Geophys Res.-Oceans (1978-2012), 98, 4793-4807, 1993.

Garcia, M. H.: Depositional turbidity currents laden with poorly sorted sediment, J. Hydraul. Eng.-ASCE, 120, 1240-1263, 1994.

Herrmann, M. J. and Madsen, O.: Effect of stratification due to suspended sand on velocity and concentration distribu- 
tion in unidirectional flows, J. Geophys. Res., 112, C02006, doi:10.1029/2006JC003569, 2007.

Middleton, G. V.: Experiments on density and turbidity currents: I. Motion of the head., Can. J. Earth Sci., 3, 523-546, 1966 a.

Middleton, G. V.: Experiments on density and turbidity currents: II. Uniform flow of density currents, Can. J. Earth Sci., 3, 627-637, 1966b.

Middleton, G. V.: Sediment Deposition from Turbidity Currents, Annu. Rev. Earth Planet. Sc., 21, 89-114, 1993.

Muste, M., Yu, K., Fujita, I., and Ettema, R.: Two-phase flow insights into open-channel flows with suspended particles of different densities, Environ. Fluid. Mech., 9, 161-186, 2009.

Özgökmen, T. M. and Chassignet, E. P.: Dynamics of TwoDimensional Turbulent Bottom Gravity Currents, J. Phys. Oceanogr., 32, 1460-1478, 2002.

Parker, G., Garcia, M., Fukushima, Y., and Yu, W.: Experiments on turbidity currents over an erodible bed, J. Hydraul. Res., 25, 123-147, 1987.
Sequeiros, O., Spinewine, B., Beaubouef, R., Sun, T., García, M., and Parker, G.: Characteristics of Velocity and Excess Density Profiles of Saline Underflows and Turbidity Currents Flowing over a Mobile Bed, J. Hydraul. Eng., 136, 412-433, 2010.

Sequeiros, O. E., Naruse, H., Endo, N., Garcia, M. H., and Parker, G.: Experimental study on self-accelerating turbidity currents, J. Geophys. Res.-Oceans, 114, C05025, doi:10.1029/2008JC005149, 2009.

Simpson, J. and Britter, R.: The dynamics of the head of a gravity current advancing over a horizontal surface, J. Fluid Mech., 94, 477-495, 1979.

Vanoni, V. A.: Transportation of suspended sediment in water, Trans. Am. Soc. Civ. Eng., 111, 67-133, 1946.

Villaret, C. and Trowbridge, J. H.: Effect of stratification by suspended sediments on turbulent shear flows, J. Geophys. Res., 96, 10659-10680, 1991.

Xu, J. P., Noble, M. A., and Rosenfeld, L. K.: In-situ measurements of velocity structure within turbidity currents, Geophys. Res. Lett., 31, L09311, doi:10.1029/2004GL019718, 2004. 